\title{
The Influence of Opposing Flow and Its Separation of SBF over Masan on Southeast Coast of the Korea
}

\author{
Hyo Eun Ji, Kwi Ok Lee ${ }^{1)}$, Soon-Hwan Lee ${ }^{2)}$, Soon-Young Park, Won-Bae Jeon and Hwa Woon Lee* \\ Division of Earth Environmental System, Pusan National University, Busan 609-735, Korea \\ ${ }^{1)}$ Atmospheric Environment \& Information Research Center, Inje University, Busan 633-165, Korea \\ ${ }^{2)}$ Institute of Environmental Research, Pusan National University, Busan 609-735, Korea \\ *Corresponding author. Tel: +82-10-510-2291, E-mail: hwlee@pusan.ac.kr
}

\begin{abstract}
A Sea breeze front (SBF) appears clear particularly if there is opposing wind, and the convergence zone along a SBF affects air quality in coastal areas. This study analyzes features of SBF separation in the presence of an opposing flow in the southeastern coastal area of Korea Peninsula. Using a Regional Atmospheric Modeling System (RAMS) numerical simulation and an opposing flow, two types of SBF were observed at Masan coastal area of Korea. In one, the SBF penetrated inland despite of the opposing flow at Jinhae (1100 LST), Wondong (1700 LST), Saenglim (1700 LST), and Miryang (1700 LST). In the other, the SBF remained on the coastline along with Jinhae (1100 LST), Masan (1400 LST), Jinbuk (1400 LST), and Gaecheon (1700 LST), because the inflow of the sea breeze was not sufficient to penetrate inland against the opposing flow. This study shows that SBFs are affected by the formation of an opposing flow, as well as the inflows of a sea breeze and the opposing flow.
\end{abstract}

Key words: Sea breeze, SBF, Opposing flow, Wind profiler, RAMS

\section{INTRODUCTION}

Sea breezes develop in coastal areas due to differences in heat capacity within the planetary boundary layer (PBL). Since a lot of industrial and downtown areas of cities are located along coastal areas, these areas are likely to suffer from severe air pollution, and many scientists have studied the air contaminants in such areas. A SBF is cooler and heavier air meets a warm air mass from the land, similar to the formation of a cold front (Simpsons, 1994). Miller et al. (2003) argued that SBF are typically located around the edges of inland areas which contain sea-breeze dense currents and sea-breeze circulation associated with temperature, humidity, and wind, and that they are sometimes formed in association with the development of cumuliform clouds on a clear day. They also mentioned that the factors in the development of SBF are promoted by a sharp temperature gradient over a narrow horizontal distance and strong convergence in the low level; a convergence in the low level can occur in the presence of strong, opposing offshore winds and strong onshore winds within the marine air mass.

A study by Asimakopoulos et al. (1999) explained that the movement of a sea breeze slows noticeably on land impact and in the vertical structure when resisting opposing winds. According to Gilliam et al. (2004), the contour and flow of a coastline are the major determinants of the spatial evolution of sea breezes. A more recent study (Malda et al., 2007) reported that SBF are affected by land surface conditions, and the results of numerical experiments showed that the development of these fronts is more affected by the convergence of friction than that of heat. Another study of the dynamics of the heat island effect and SBF argued that cities impact the delay and movement of SBF (Dandou et al., 2009). Furthermore, Suresh (2007) examined the characteristics of SBF by analyzing such a front in Southern India (particularly the length of the front and the depth of the breeze) using Doppler radar data. While sea breezes have been actively studied in Korea (Moon et al., 1999; Lee, 1986), SBF have not, because the equipment and observation process are too expensive to not use upper layer data easily.

There have been improvements in this area of research in the last decade; specifically, the adoption of new observation equipment such as wind profilers and radiosondes has enabled upper air observation, which has resulted in the development of data and equipment from other relevant institutes, and is producing more in-depth observation of SBF. A Korean study by Lee and Han (1992) examined the vertical distribution of aerosol particles in the boundary layer using a captive 
balloon during the development of a SBF. The results showed that there were many differences in the number concentrations of aerosols in the sea-breeze layer. Another study by Jeon (1997) argued that SBF impact $\mathrm{SO}_{2}$ concentration, which implies that predictions of the development of SBF through the observation of upper air with a radiosonde could reduce air pollution. Thus, sea breezes, as well as the movements and circulations of SBF, are likely to transport air contaminants to influence the air quality in coastal areas via mesoscale circulation.

Recent studies using wind profilers have focused on harbor locations and include the industrial complexes around Changwon and Jinhae. This area is important for pollutant transport associated with sea breeze development because of the air flow and dispersion characteristics as well as the geographical location. Also, using five years of wind profiler data, it is easy to analyze a three-dimensional SBF because analysis of the upper air is now possible.

This study analyzed the days on which SBF were observed were selected from the data, which lacked spatially detailed vertical observations, in order to conduct a three-dimensional numerical experiment. Therefore, we conducted a comparative analysis of SBF based on the interaction between sea breezes and opposing flows on the coast of Masan City on August 9, 2006 using the data of other coastal cities in order to examine the characteristics of SBF.

\section{DATA AND MODEL CONFIGURATION}

In order to determine the days on which SBF occurred, observation data from the Auto Weather System (AWS), radiosonde, and wind profiler were analyzed. A radiosonde measured pressure, temperature, humidity, and wind speed and at altitude between 20 and $30 \mathrm{~km}$. Although there are observation networks throughout the world, five observatories in Pohang, Gosan, Baengyeongdo, Sokcho, and Heuksando run the main operations of the system. Two U.S. army bases in Osan and Gwangju also collect data twice a day.

Wind profilers are used to monitor microscale to mesoscale severe weather and are characterized by an ability to measure continuously and to collect data remotely using radio waves. These tools measured the direction and speed of both horizontal and vertical wind, turbulence intensity, precipitation intensity, and the altitude of the inversion layer. There are ten wind profilers in Korea, in Haenam, Munsan, Gangneung, Gunsan, Masan, Uljin, Wonju, Chupungryong, Cheorwon, and the oceanic meteorological observation complex in the Yellow Sea. Radiosondes and wind profilers are particularly useful for three-dimensional analysis of the atmosphere and measurement of the vertical elevation of SBF.

To select days that sea breeze occurre with clear SBF, we used AWS and wind profiler data including the wind speed and direction, and temperature.

\subsection{The Model and Its Domains}

A model used to determine the proper study days was the Regional Atmospheric Model System(RAMS) developed by Pielke et al. (1992), which can carry out numerical simulation of large-scale eddies and mesoscale thunderstorms. This model uses polar stereographic data based on the Arakawa C-grid using incompressible and non-hydrostatic equations and consists of a coordinate system in accordance with the vertical topography. For the calculation of physical processes, the Mahrer-Pielke scheme (Mahrer and Pielke, 1977) was used for radiation, the Kuo cumulus scheme (Tremback, 1990) was used for clouds and precipitation, and the Mellor-Yamada scheme (Mellor and Yamada, 1982) was used to determine the eddy vertical diffusion coefficients. The first input field used NCEP-CDAS reanalysis data. Three-second topography data was used for numerical simulation based on the NASA Shuttle Radar Topography Mission (SRTM) in order to reflect the changes in meteorology due to topography.

Coastal areas with cities were selected as the target areas for the analysis of the movement, development, disappearance, and circulation of sea breezes and SBF. Four horizontal domains were studied: the external domain lattice had a structure of $67 \times 67$, and the internal domain lattice had a structure of $74 \times 74$. The resolutions for these domains were set to $30,9,3$, and $1 \mathrm{~km}$. The third domain included parts of Gyeongsangnam-do, Pohang, and Gyeongsangbuk-do, and the last domain focused on Masan and Gyeongsangnam-do, including the majority of Geojedo and parts of Busan and Yangsan. The vertical layer structure consisted of a total of 30 layers at intervals of $1.15 \mathrm{~km}$, with the bottom layer located at $50 \mathrm{~m}$. The numerical simulation model is shown in Table 1, and the final domain is shown in Fig. 2.

Table 1. Configurations for the RAMS numerical simulation.

\begin{tabular}{|c|c|c|c|c|}
\hline & Domain 1 & Domain 2 & Domain 3 & Domain 4 \\
\hline Hori & $67 \times 67$ & $74 \times 74$ & $74 \times 74$ & $74 \times 74$ \\
\hline $\begin{array}{l}\text { Horizontal } \\
\text { resolution }\end{array}$ & $30 \mathrm{k}$ & 101 & $3.3 \mathrm{~km}$ & $1.1 \mathrm{~km}$ \\
\hline Physical option & \multicolumn{4}{|c|}{$\begin{array}{l}\text { Cumulus parameterization scheme: Kuo } \\
\text { Radiation scheme: Mahrer \& Pielke } \\
\text { PBL scheme: Mellor \& Yamada }\end{array}$} \\
\hline Time period & $\begin{array}{l}2006.8 .6 . \\
-2006.8 .1\end{array}$ & $\begin{array}{l}1800 \mathrm{UTC} \\
0.1700 \mathrm{UT}\end{array}$ & & \\
\hline
\end{tabular}




\section{RESULTS}

\section{1 SBF Days}

Fig. 1 shows the analysis used to determine the days on which sea breezes or SBF were observed on Masan coasts over the five years from 2004 to 2008. The results show that sea breezes occurred most frequently (14 times both in 2004 and 2006), and that the greatest number of SBF was observed in 2006. The year 2006 was an unusual year in which sea breezes front were observed over a long period of time compared to those in other years, and they were also distinctly observed using the vertical measurements of wind profilers.

Particularly, on the August 8-9, 2006, both a sea breeze and a SBF were clearly observed by wind profilers. Thus, the model for numerical simulation was carried out from August 7-10, 2006 and focused on August 9.

Fig. 3(a)-(c) shows the temperature, relative humidity,

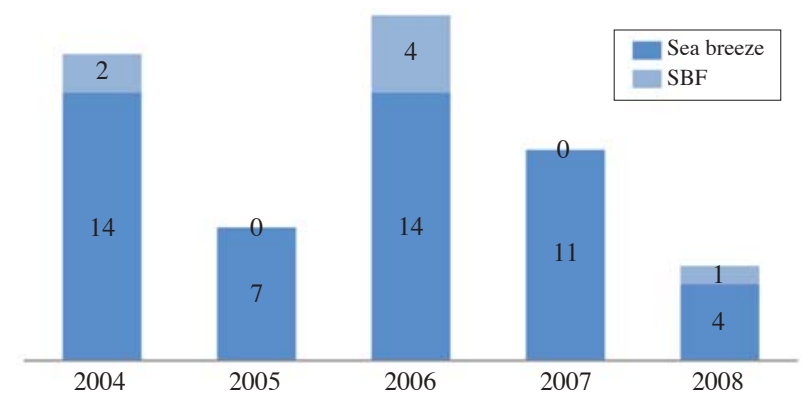

Fig. 1. Wind profiler data used for the analysis of sea breeze and SBF occurrences over Masan from April 2004 to August 2008.

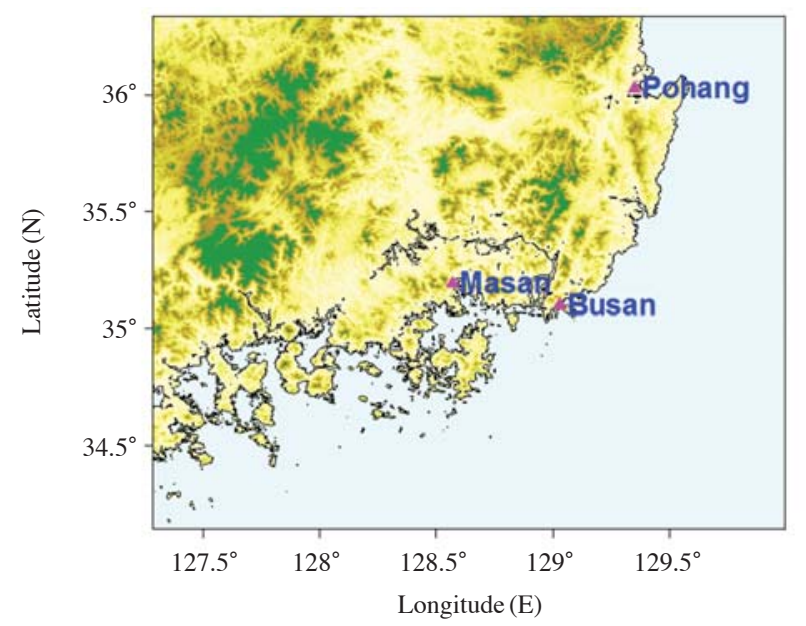

wind speed and direction, and wind profiler for a SBF that occurred on the $9^{\text {th }}$ of August, 2006. Between 1300 and 1400 LST, the difference in temperature was 2.8 ${ }^{\circ} \mathrm{C}$, the wind speed increased by $4.3 \mathrm{~m} \mathrm{~s}^{-1}$, the wind direction shifted from east to southeast, and the relative humidity increased by $15 \%$, indicating the formation of a SBF due to the convergence of cool, humid air from the sea and warm air from the land. In the upper layers above $1,000 \mathrm{~m}$ of wind profiler, the wind shifted from the northeast to the east and again to the north in the afternoon. In the bottom layers, the wind at dawn was from the northeast and east, shifted to the north later in the morning, and continued until noon as a land breeze. Strong southern wind speeds up to $2-3 \mathrm{~m} \mathrm{~s}^{-1}$ were observed in the late afternoon;

At 2300 LST, the wind direction shifted from south to southwest and the wind speed decreased, demonstrating that the sea breeze changed to a land breeze. And the wind vector of profiler shifted to the southeast.

The SBF developed along with the sea breeze between 1300 and 1400 LST. This is the typical result of changes in wind systems and is similar to terrestrial observations. In addition, the boundary between the south and north winds in the upper and bottom layers, respectively, indicates the development of a SBF, and the height at this boundary can be considered as the altitude of the SBF.

\section{2 Results and Verification of the Numerical Simulation}

\section{2. 1 Horizontal Analysis}

Fig. 4 shows horizontal wind fields according to the RAMS. The northeast wind flowed in the coastal area around Masan, while a sea breeze had not yet

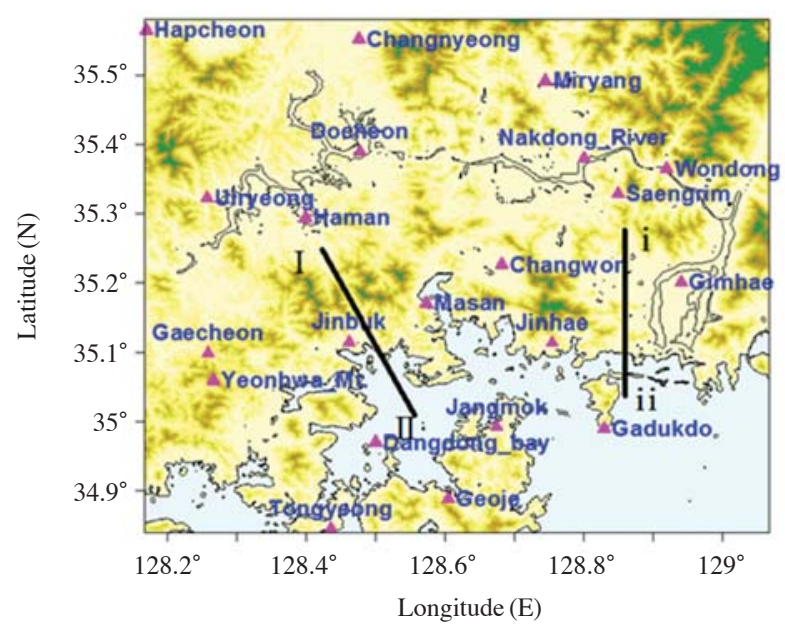

Fig. 2. Modeling domains 3 (left) and 4 (right) at the observation stations ( $\mathbf{\Delta}$ ). Solid lines (I-II and i-ii) are used to analyze the $\mathrm{Y}-\mathrm{Z}$ cross-section. 


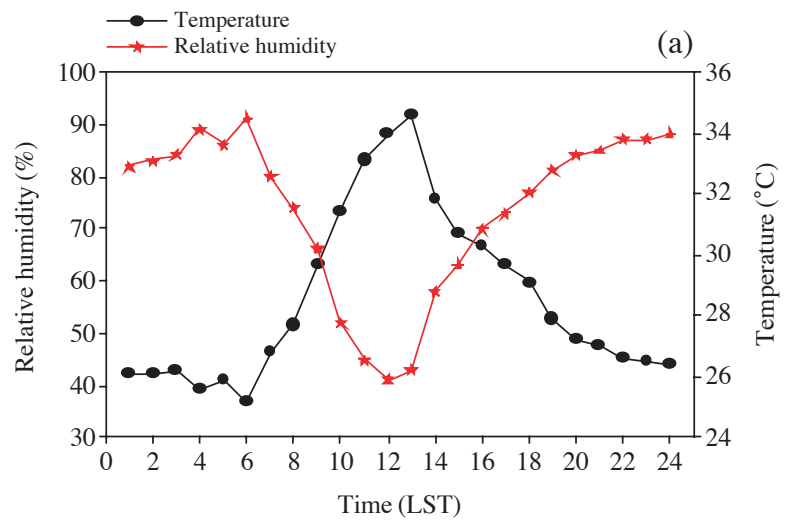

collided at 1000 LST. Eventually, a strong sea breeze with a maximum speed of $7.0 \mathrm{~m} \mathrm{~s}^{-1}$ was produced and reached the interior of the domain at 1100 LST. Sea breezes developed on the Masan and Jinhae coasts, and their directions changed rapidly in Gadukdo and Jinhae Bays, where the pervious sea breeze had occurred.

The SBF entering Jinhae and Changwon permeated deep into the interior at an average speed of $1-2 \mathrm{~m} \mathrm{~s}^{-1}$, and the SBF opposing the land breeze on the top of Yeonhwa Mountain finally reached the summit with the increased speed of $4 \mathrm{~m} \mathrm{~s}^{-1}$ at 1200 LST. However, a sea breeze that had been permeating since the steep slopes around Yeonhwa Mountain decreased the wind speed, and the low ground in Jinhae and Changwon affected the SBF so that it reached the Nakdong River at an average speed of 5-6 $\mathrm{m} \mathrm{s}^{-1}$. By 1500 LST, the SBF affected only a small inland area after it swept across nealy the entire domain at a speed of $10.0 \mathrm{~m} \mathrm{~s}^{-1}$.

Through $100 \mathrm{~m}$ (Fig. 5) and $500 \mathrm{~m}$ (Fig. 6) in the $w$ component, we examined the process evolution and movement of the SBF. At most points on the Masan coast, the descending zone was dominant over the ascending zone, but the surrounding areas of the Masan and Jinhae coasts, as well as Miryang and Changnyeong, showed gradual ascending zones due to opposing flows. Afterward, a $20 \mathrm{~m} \mathrm{~s}^{-1}$ ascending zone developed and moved $17.5 \mathrm{~km}$ inland, after which it moved $26 \mathrm{~km}$ from the coast and developed to possess a more complex appearance. The ascending zone that developed along the Masan and Jinhae coasts at 1200 LST moved faster to Changnyeong and Gwanryong Mountain with a grade of $40^{\circ}$ (increased by $10^{\circ}$ ). As in the numerical simulation of the horizontal wind field, this shows that the front passing over the land was faster than the front passing over the coast.

Using the same method we analyzed the horizontal $w$ component at an altitude of $500 \mathrm{~m}$ using a wind profiler, as shown in Fig. 3(c). The horizontal $w$ component moved westward due to the easterly wind, weakened in the coastal areas except for Jinhae starting at 1200 LST, and moved to Gaecheon, Saenglim, Wondong, and Miryang, where $w$ increased.

Fig. 3. Time series of temperature and relative humidity (a), wind speed and wind direction (b), and wind profiler data (c) observed at Masan station on Aug. 9, 2006.

developed in the coastal area around Jinhae because of the prevalence of the north wind at 0800 LST. The wind direction started to change to an easterly wind at the same time as the south wind blowed from the sea in all coastal areas, such as Dangdong Bay and Jinhae Bay. Specifically, the sea breeze from the Jinhae coast and the land breeze from the Changwon interior

\section{2. 2 The Vertical Analysis}

Fig. 7 shows the wind velocity and the potential temperature field of the vertical cross-section of Y-Z located in the coastal areas, illustrating the movements of the SBF along the coasts (a, I-II) and along inland areas (b, i-ii). In (a), at the $-4 \mathrm{~km}$ point in the X-direction at 1100 LST, a SBF occurred due to the convergence of a sea breeze and land breeze, and the vectors converged to an altitude of about $700 \mathrm{~m}$, the height of the SBF. Two hours later, at the $7 \mathrm{~km}$ point in the $\mathrm{X}$ direction, the front was growing and the ascending 

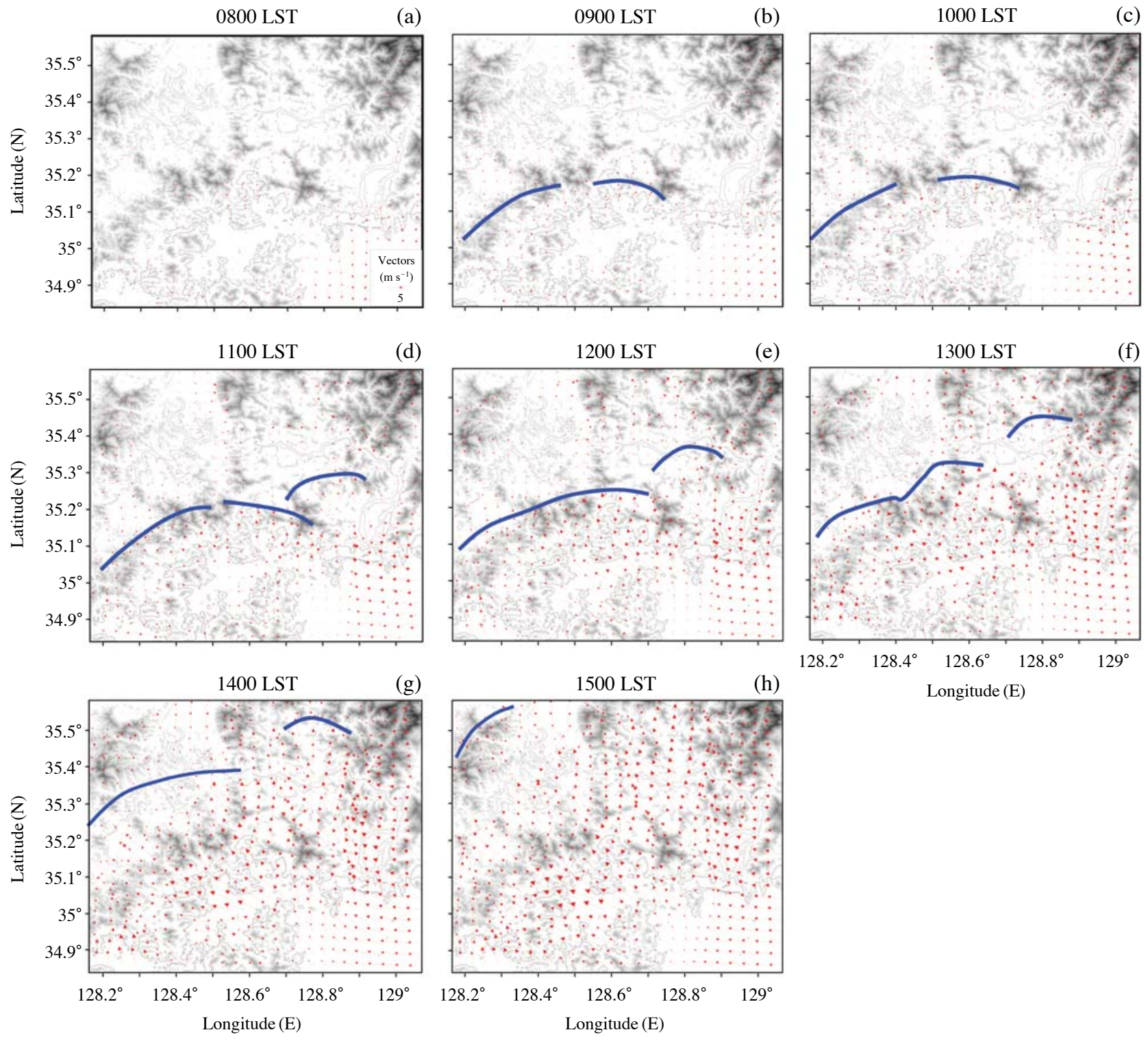

\section{(h)}

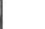



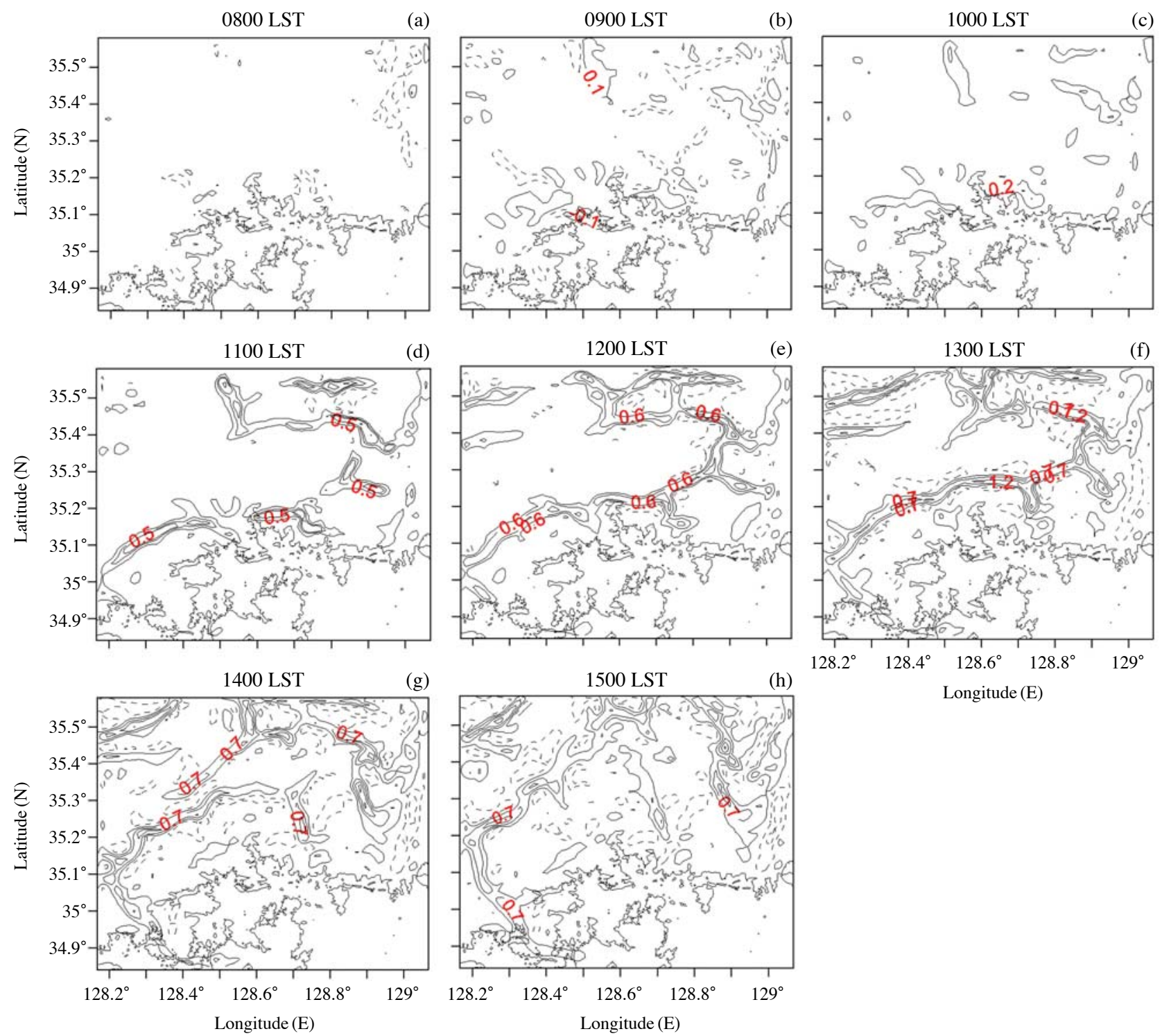

Fig. 5. Same as Fig. 4 but for the horizontal $w$ component at a $100 \mathrm{~m}$ height. Solid and dash line indicate upward and downward motion of $w$ component, respectively. Contours range from -1.3 to $2.4 \mathrm{~m} \mathrm{~s}^{-1}$, with an interval of $0.5 \mathrm{~m} \mathrm{~s}^{-1}$.

Fig. 4, the strong convergence zone of the SBF formed with the inflow of a fast sea breeze, and then it was to move quicken a speed of front.

In summary, the vertical ascending flow was small when the gradient of potential temperature was small through the vertical potential temperature and the vector field, and the appearance of the horizontal movement according to the size of the opposing flow was represented by the vertical vectors. This feature has something in common with the difference in potential temperature gradients and convergence between land air and sea surface air masses caused by the development of the SBF, as discussed by Miller $e t$ al. (2003).

Fig. 8 shows a comparison of the results from the numerical simulation and the observed values of radiosonde data in Pohang. The analysis of the potential temperature and the relative humidity from the vertical profiler shows that, at 0900 LST (a), the observed value and the experimental value of the potential temperature on the ground were $299.1 \mathrm{~K}$ and $298.9 \mathrm{~K}$, respectively, and $307.1 \mathrm{~K}$ and $304.7 \mathrm{~K}$, respectively, at an altitude of $1,500 \mathrm{~m}$. However, at $2100 \mathrm{LST}$ (b) the temperatures were $301.1 \mathrm{~K}$ and $300.8 \mathrm{~K}$ on the ground and $307.5 \mathrm{~K}$ and $308.0 \mathrm{~K}$ at an altitude of $1,500 \mathrm{~m}$, respectively. The difference between the results is small, which indi- 


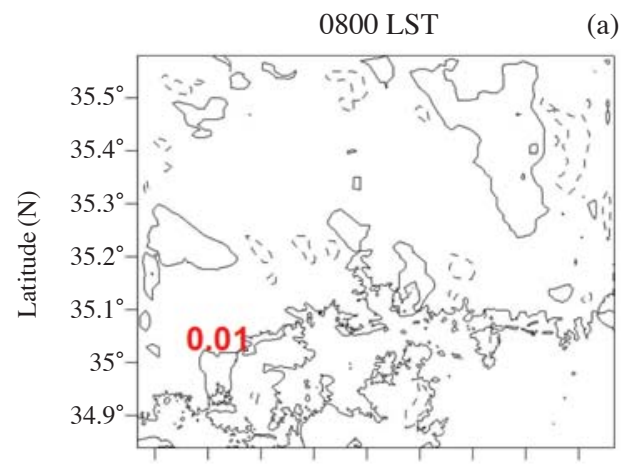

(a)

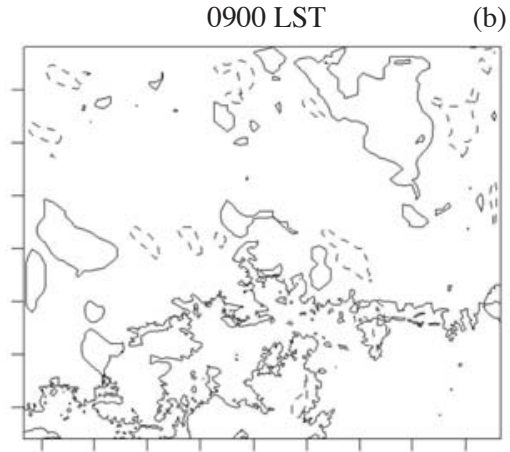

(b)
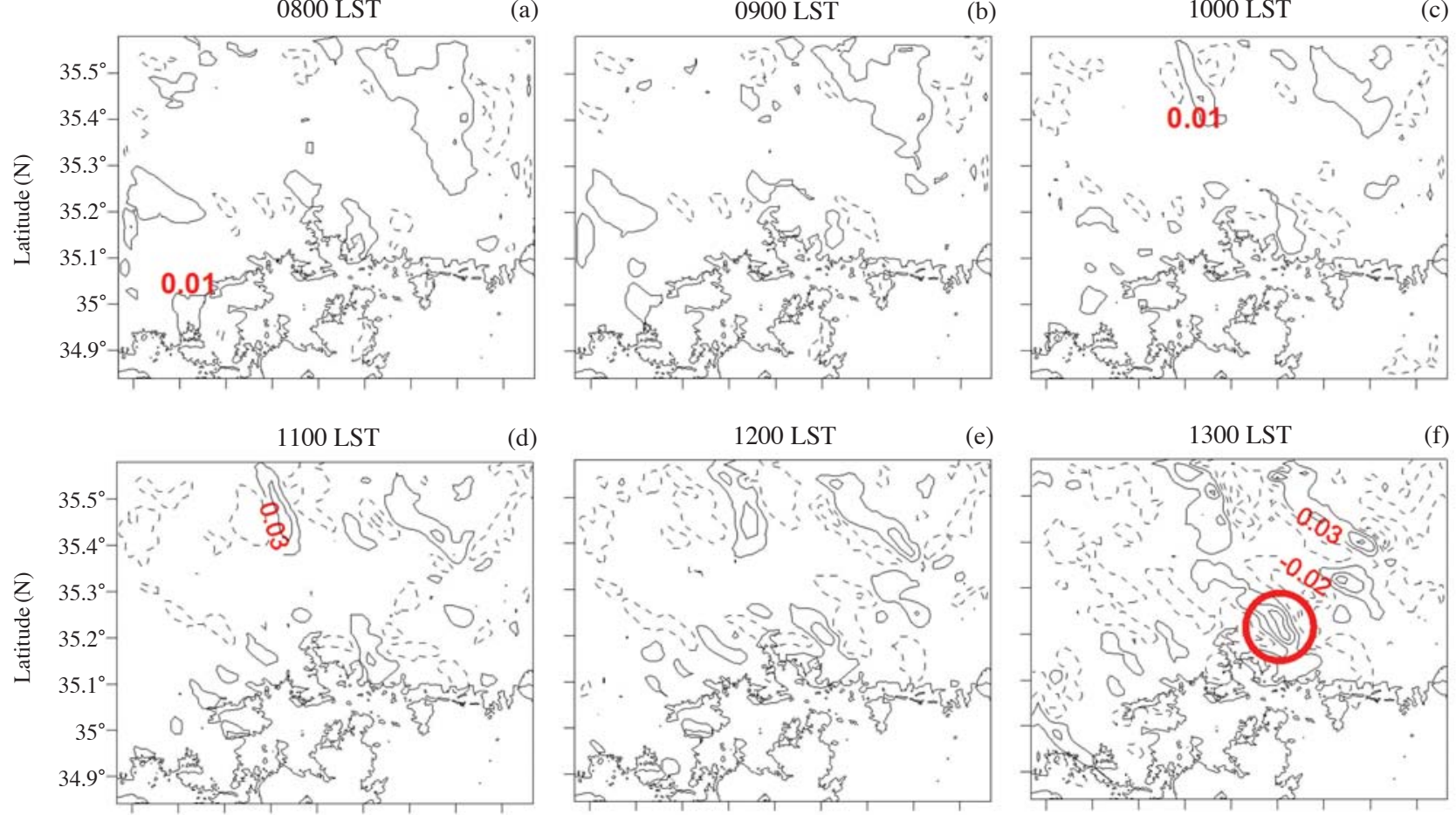

(d)
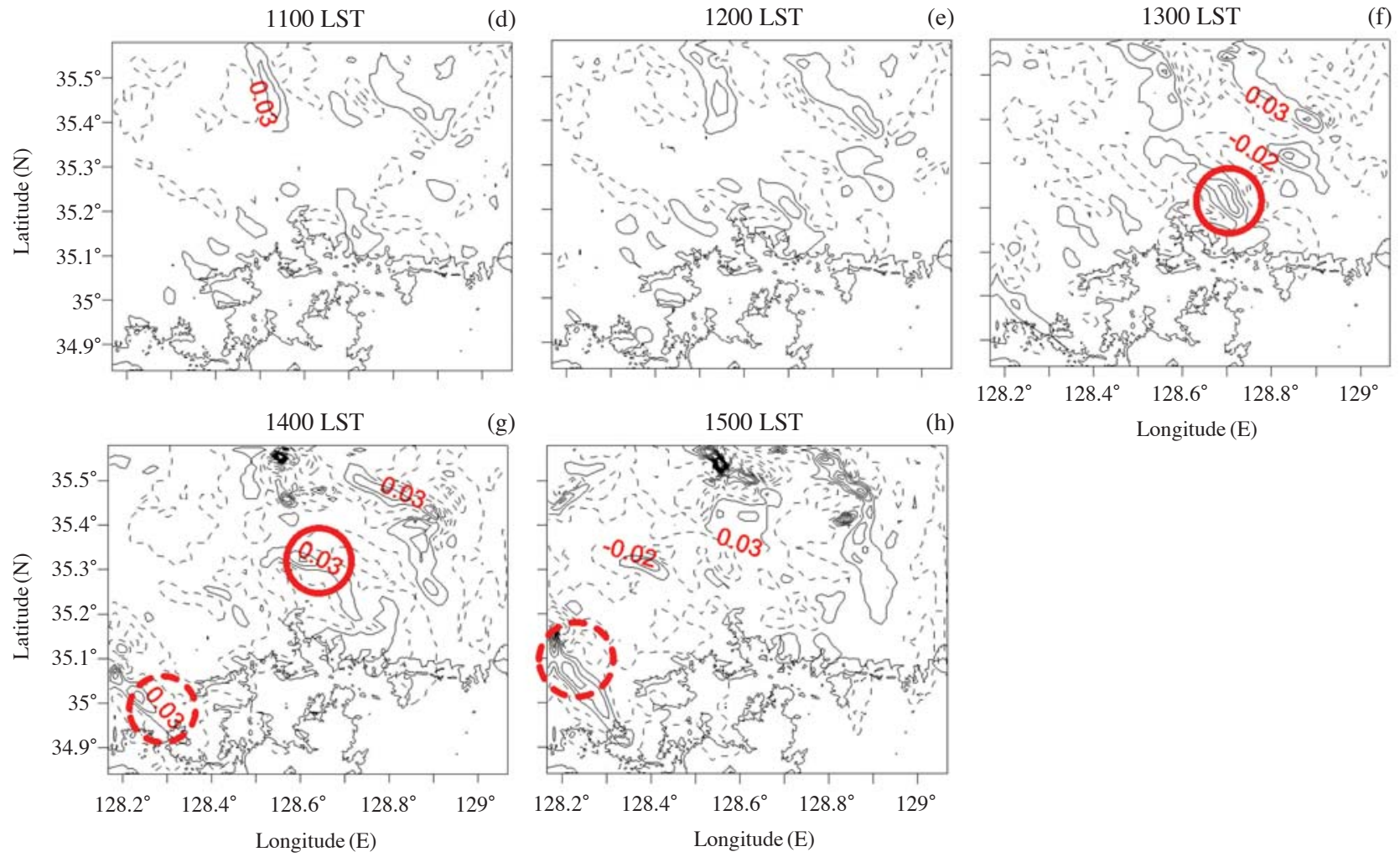

Fig. 6. Same as Fig. 5 but for the horizontal $w$ component at a $500 \mathrm{~m}$ height. Circles indicate the motion of the $w$ component. Contours range from -0.42 to $0.74 \mathrm{~m} \mathrm{~s}^{-1}$, with an interval of $0.05 \mathrm{~m} \mathrm{~s}^{-1}$.

cates a successful numerical simulation. As for the relative humidity, the observed value dropped to $44 \%$ and then increased until an altitude of about $800 \mathrm{~m}$ in the daytime. A similar pattern was observed (although the decrease and increase repeated many times) at altitudes no higher than $2,000 \mathrm{~m}$. On the other hand, at $0900 \mathrm{LST}$, the RAMS increased by $65.4 \%$ up to an altitude of $300 \mathrm{~m}$ and decreased until an altitude of $1,000 \mathrm{~m}$. At $2100 \mathrm{LST}$, the RAMS increased by $71.5 \%$ up to an altitude of $150 \mathrm{~m}$ and then decreased again.

In addition, the numerically simulated $v$ component was drawn at regular intervals according to the vertical height in Masan for vertical analysis of the permea- tion of sea breezes (Fig. 9). The left segment of the dotted line represents the component of the north wind ( - , offshore wind), and the right part represents the component of the south wind $(+$, onshore wind). At 0700, 0900, and $1100 \mathrm{LST}$, the north wind appeared on the ground, but the component of the south wind at a speed of greater than $7.0 \mathrm{~m} \mathrm{~s}^{-1}$ appeared at 1300 LST at altitudes less than $500 \mathrm{~m}$. According to the vertical profiler, the wind shifted to the north at the altitude of $600 \mathrm{~m}$ and again to the south at $3,200 \mathrm{~m}$. At $1500 \mathrm{LST}$, the south wind showed the maximum speed of $8.0 \mathrm{~m} \mathrm{~s}^{-1}$ at about $100 \mathrm{~m}$ and shifted to the north wind at $1,000 \mathrm{~m}$, which showed the strongest $v$ com- 

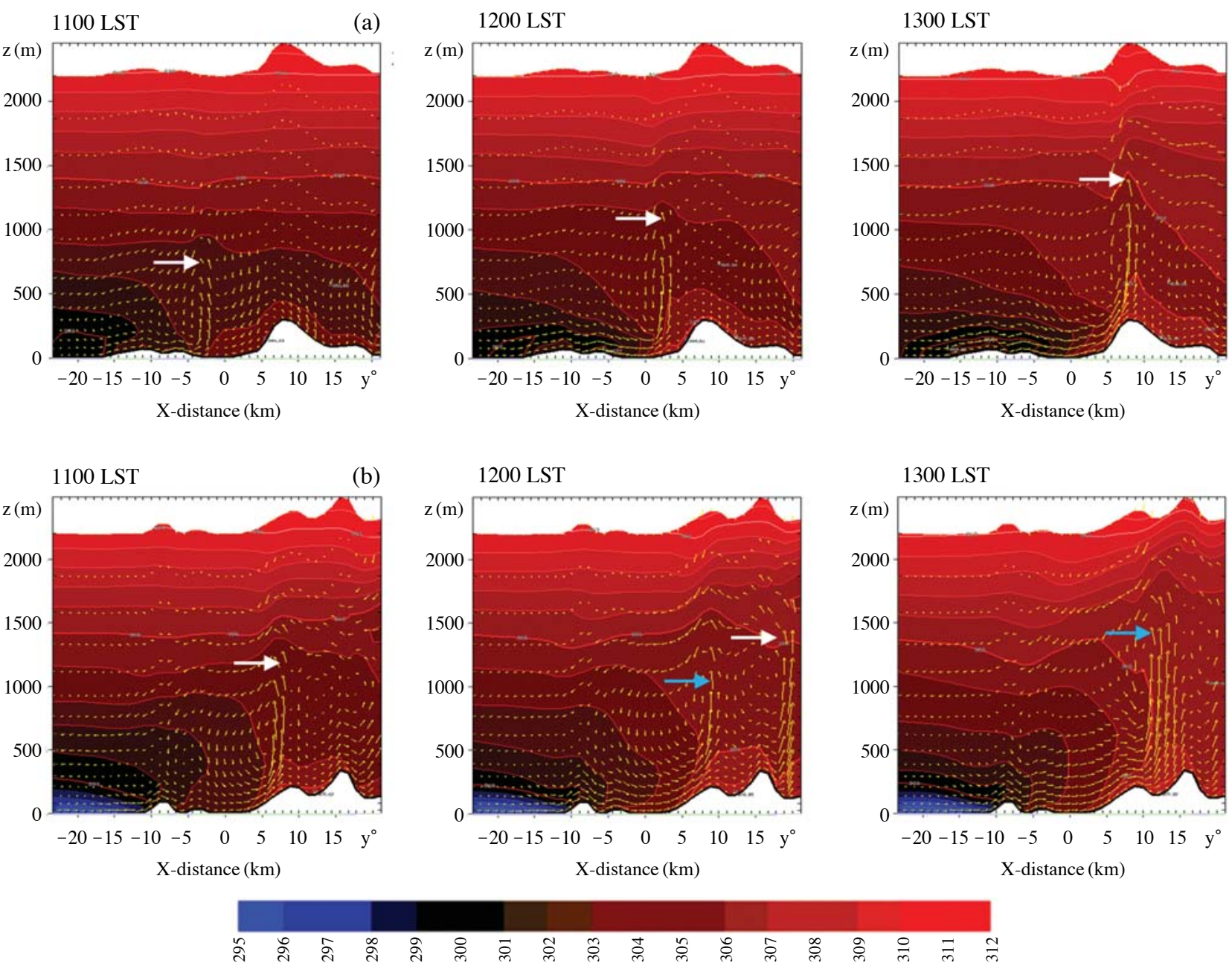

Fig. 7. Vertical Y-Z cross-sections along lines I-II (a) and i-ii (b) of wind vectors (arrow: $0.5 \mathrm{~m} \mathrm{~s}^{-1}$ ) and potential temperature (shaded: $1 \mathrm{~K}$ ). Surface topography is shown with a black solid line. Thick arrows mark location of front.

ponent of more than $6 \mathrm{~m} \mathrm{~s}^{-1}$ at $1,800 \mathrm{~m}$. This means that a stronger sea breeze on the ground correlates to a stronger return flow (offshore wind). The depth of the sea breeze increased over time, as shown in Fig. 9(b). As of $1700 \mathrm{ST}$, the south ground wind at about $7.0 \mathrm{~m} \mathrm{~s}^{-1}$ strengthened, showing a speed of $8.0 \mathrm{~m} \mathrm{~s}^{-1}$ at $200 \mathrm{~m}$, and then shifted to the north at $1,300 \mathrm{~m}$. At $1900 \mathrm{LST}$, the wind at $5.0 \mathrm{~m} \mathrm{~s}^{-1}$ strengthened, showing a speed of $7.0 \mathrm{~m} \mathrm{~s}^{-1}$, and then shifted to the north at $1,500 \mathrm{~m}$. In other words, the sea breeze was formed at 1300 LST, and the wind speed of the SBF increased over time at altitudes of $600 \mathrm{~m}, 1,000 \mathrm{~m}$, and $1,300 \mathrm{~m}$.

\section{3 The Time Series and Statistical Analysis}

Fig. 10 shows the daily observed and model values of the temperature and wind speed at each observation station. The observed time series of the wind speed showed $0.3 \mathrm{~m} \mathrm{~s}^{-1}$ at $0900 \mathrm{LST}$ in Jinhae (c) and $2.7 \mathrm{~m}$ $\mathrm{s}^{-1}$ at 1100 LST. In Masan (a), the wind speed increased by about $5 \mathrm{~m} \mathrm{~s}^{-1}$ in one hour, from $1.1 \mathrm{~m} \mathrm{~s}^{-1}$ (1300 LST) to $6.2 \mathrm{~m} \mathrm{~s}^{-1}$ (1400 LST). In Jinbuk (d), the wind speed increased by $3.1 \mathrm{~m} \mathrm{~s}^{-1}$ over the same time, while the $0.5 \mathrm{~m} \mathrm{~s}^{-1}$ wind in Gaecheon (h) at 1500 LST increased to $2.7 \mathrm{~m} \mathrm{~s}^{-1}$ at $1700 \mathrm{LST}$ and remained at that speed for a few hours. Inland at Saenglim, the wind speed was $1.0 \mathrm{~m} \mathrm{~s}^{-1}$ at $1500 \mathrm{LST}$ and $2.7 \mathrm{~m} \mathrm{~s}^{-1}$ two hours later. At the same time, in Wondong (f), a wind speed of $4.3 \mathrm{~m} \mathrm{~s}^{-1}$ was measured and permeated deep into Miryang (e), showing a speed of $3.0 \mathrm{~m} \mathrm{~s}^{-1}$ at $1800 \mathrm{LST}$.

The route above can be classified as follows. The sea breeze that began at 0900 LST developed as a SBF moving along the coastal areas of Jinhae (1100 LST), Masan (1400 LST), Jinbuk (1400 LST), and Gaecheon (1700 LST), while that which permeated through Jinhae (1100 LST) moved along the valley into the inland areas of Wondong (1700 LST), Saenglim (1700 LST), 

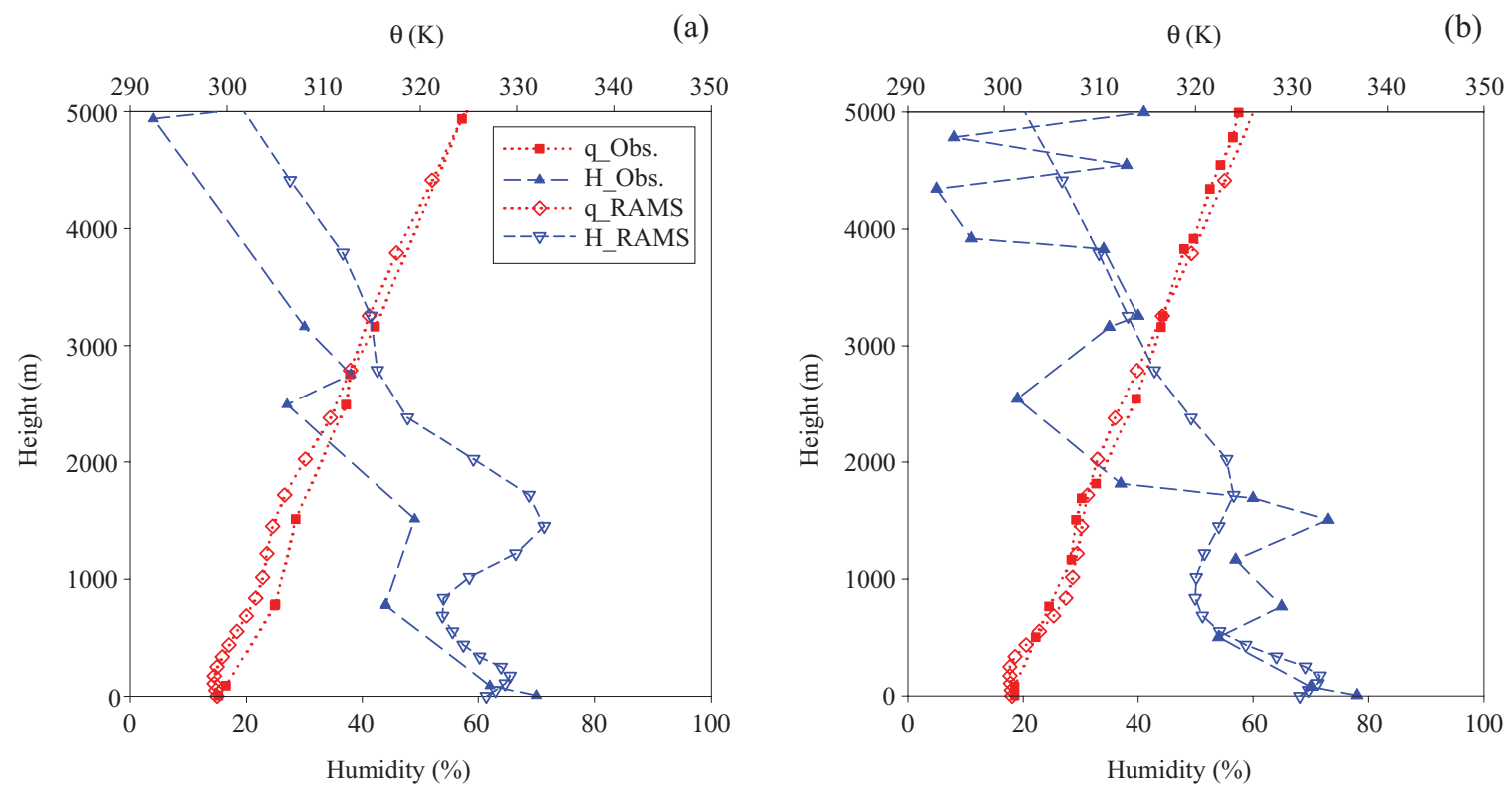

Fig. 8. The vertical profiles of potential temperature $(\theta)$ and relative humidity $(\%)$ according to observation and simulation at the Pohang site on Aug. 9, 20060900 LST (a) and 2100 LST (b).
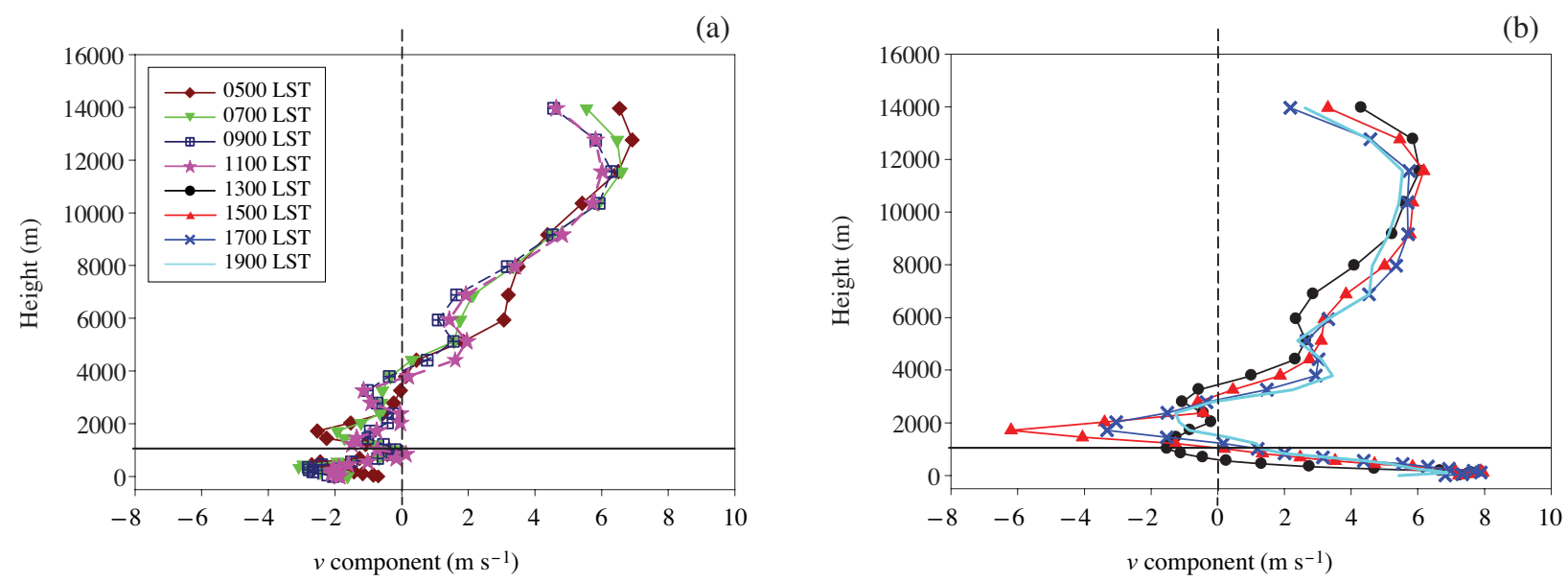

Fig. 9. Vertical profile of the simulated $v$ component at Masan station on Aug. 9, 2006. Horizontal solid line indicates a 1,000 m height, the vertical dotted line divides the $v$ component into positive (onshore wind) and negative (offshore wind) regions. Panel (a) presents the results of offshore wind at 0500 LST-1100 LST, and Panel (b) presents the results of onshore wind at 1300 LST1900 LST.

and Miryang (1700 LST). The SBF that traveled inland moved relatively slowly compared to the one moving along the coast because of the opposing flow. The model front times were calculated to occur 1-2 hours earlier than did the actual fronts.

Statistical analysis was conducted to verify the scientific validity of the time series, as shown in Fig. 11. IOA (a) showed a fair temperature result of $0.94 \pm 0.04$ at all points, and RMSE (c) also showed a low error rate (1.49 \pm 1.0$)$. Masan and Jinhae each showed 0.76 and 1.05 , which are better results than those of other areas. In the inland areas the IOA (a) and RMSE (c) of temperature showed relatively good results in Miryang $(0.97,1.54)$, and the IOA (b) and RMSE (d) of the wind speed showed good results in Saenglim(0.75, 0.97). With regard to the coastal areas, the IOA and RMSE of the temperature were 0.98 and 0.77 , and those of the wind speed were 0.88 and 0.70 in Jinbuk, 

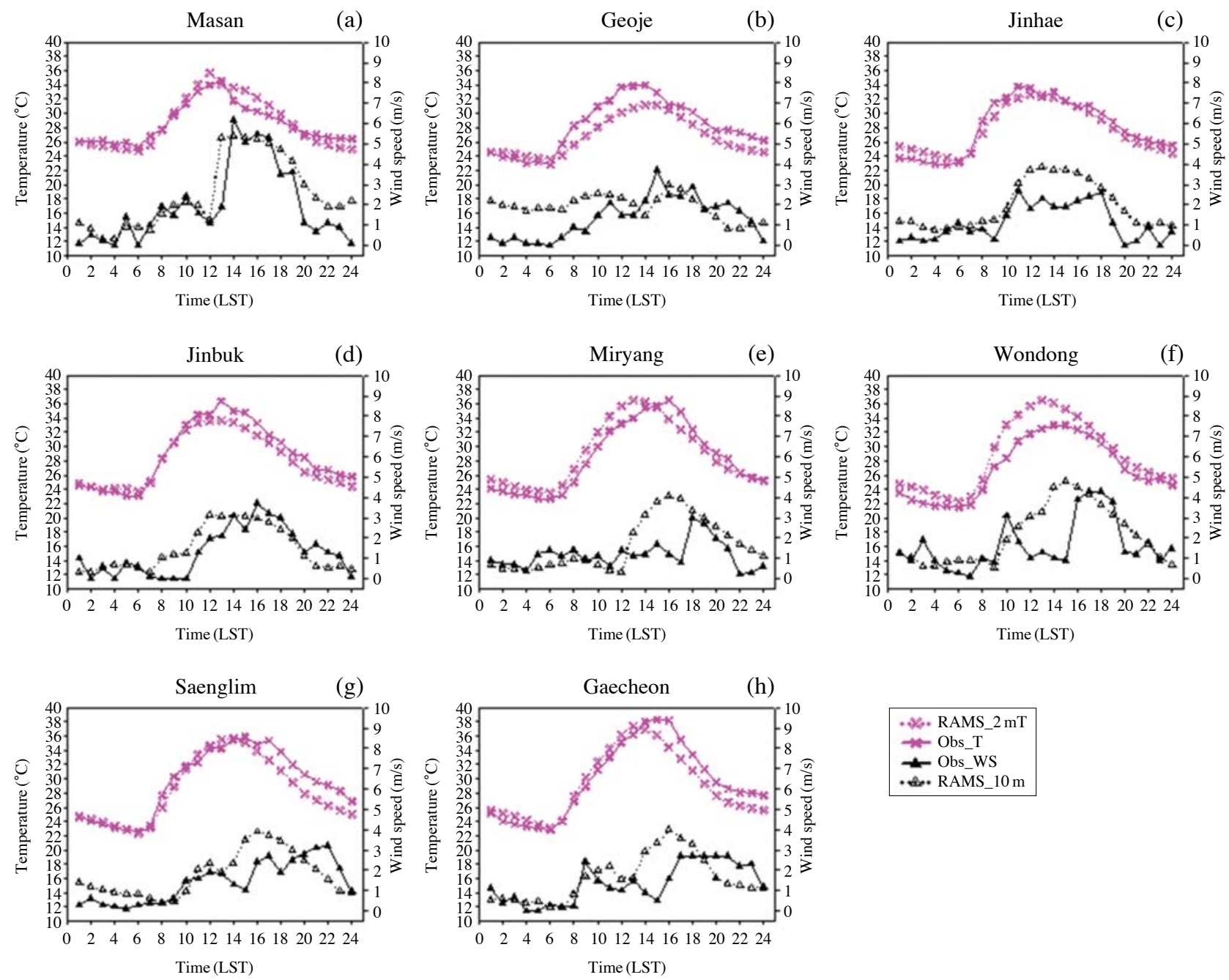

Fig. 10. Diurnal variations of $2 \mathrm{~m}$ air temperature $\left({ }^{\circ} \mathrm{C}\right.$; cross) and $10 \mathrm{~m}$ wind speed $\left(\mathrm{m} \mathrm{s}^{-1}\right.$; triangle) observed (filled) at each of the stations and simulated (empty) on Aug. 9, 2006 at Masan (a), Geoje (b), Jinhae (c), Jinbuk (d), Miryang (e), Wondong (f), Saenglim (g), Gaecheon (h).

respectively.

The results of the statistical analysis of wind speed are as follows. The IOA and RMSE of the inland areas were $0.66 \pm 0.09$ and $1.18 \pm 0.2$, respectively, while the IOA $(0.70 \pm 0.19)$ was higher and RMSE $(1.05 \pm 0.34)$ was lower in the coastal areas. These results indicate that the coastal movement of the front was more accurately modeled compared to that over land. This same tendency also applied to the temperature.

\section{SUMMARY AND CONCLUSIONS}

In this study, we analyzed separated SBF in the presence of an opposing flow, and the numerical simulation using RAMS was adopted in order to examine the characteristic of SBF.

Analysis of observation data based on AWS, wind profilers, and radiosonde data from the $9^{\text {th }}$ of August, 2006 showed that a SBF was formed around the cities of the southeast coastal areas, which was also accurately predicted using the numerical simulation. The results of the observational data showed that the formation of a SBF at 1300 LST caused a rapid drop in temperature $\left(2.8^{\circ} \mathrm{C}\right)$, an increase in relative humidity $(15 \%)$, a change in wind direction (from northeast to southeast), and an increase in wind speed $\left(4.3 \mathrm{~m} \mathrm{~s}^{-1}\right)$. The vertical observations showed that the opposing flow was observed at 1300 LST, at which time the SBF was formed. The two-dimensional analysis of the $v$ component according to altitude showed that the sea breeze was formed at the same time, and a front developed with maximum speed up to altitudes 

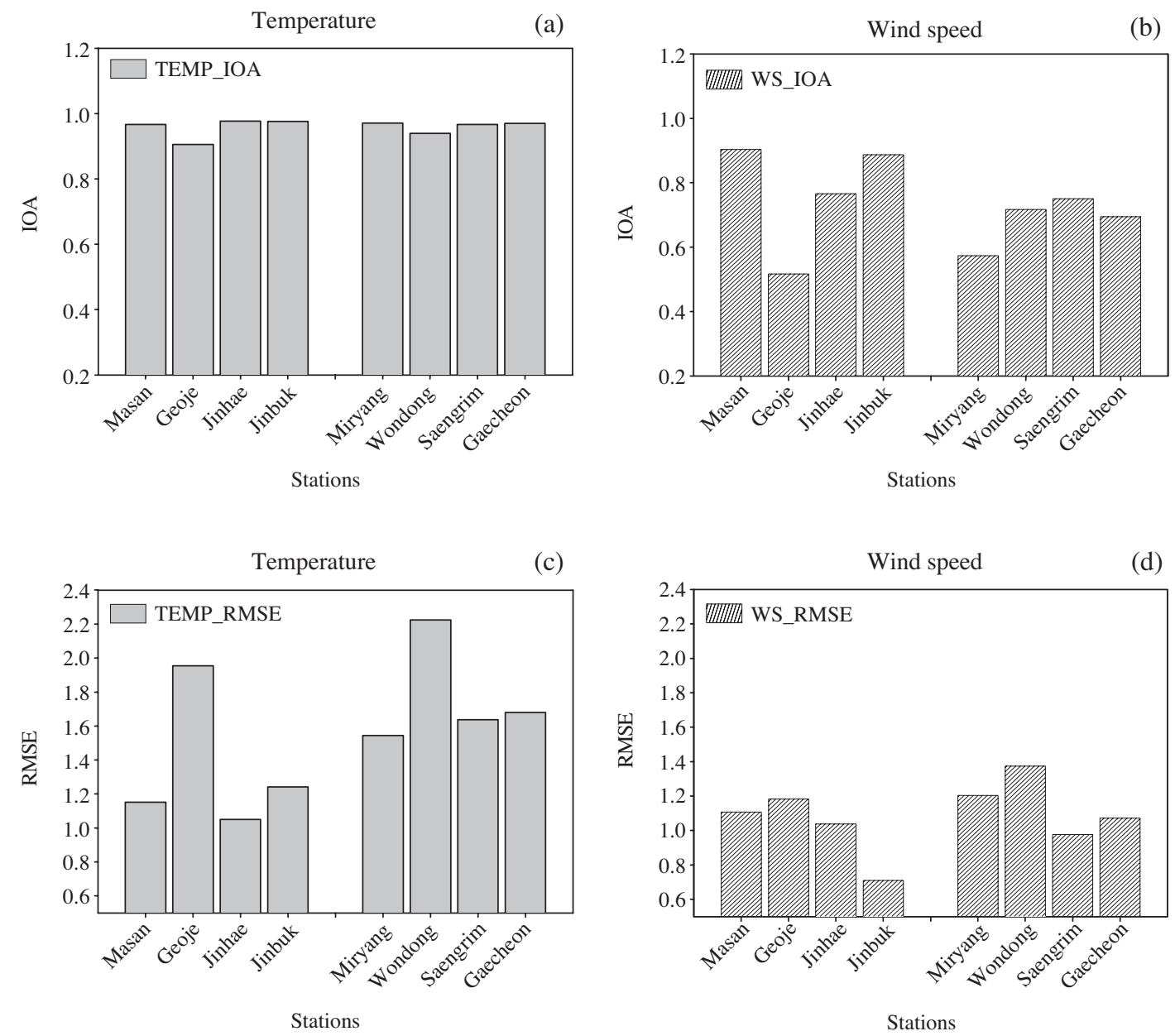

Fig. 11. Temperature (a) and horizontal wind speed (b) in terms of IOA, and temperature (c) and horizontal wind speed (d) in terms of RMSE statistics calculated for AWS stations.

\section{of $1,800 \mathrm{~m}$ at $1500 \mathrm{LST}$.}

Separated by SBF, two types of movement of the SBF were shown in this study; one SBF stayed along the coastline, while the other SBF penetrated inland despite of the opposing flow. In the former case, the front moved slowly because of the inflow of the weak sea breeze to the opposing flow, while that in the latter case moved relatively quickly because of the strong sea breeze. The result of the numerical simulation using the horizontal wind field showed that, in the former case, the sea breeze entered early in Jinhae, with a SBF being formed at 1400 LST on the Masan coast before moving along the coasts. In the latter case, a faster sea breeze entered late in Busan and Gimhae and passed through Saenglim and Miryang. This pattern also applied to the specific humidity and the $w$ component, which were also shown in the numerical simulation.

The paths of the SBF were observed, forecasted, and examined two-dimensionally at each point using the time series graph. Statistical analysis based on the results showed that the observed and numerical simulation values were matched, and the temperature and wind speed values of IOA and RMSE in the coastal areas were much improved than those in the inland areas.

The formation, speed, and movement of a SBF vary significantly in the presence of an opposing wind. Therefore, this phenomenon can affect the dispersion of pollutants in coastal areas.

\section{ACKNOWLEDGEMENT}

This work was funded by the Korea Meteorological Administration Research and Development Program under Grant CATER 2006-2205. 


\section{REFERENCES}

Asimakopoulos, D.N., Helmis, C.G., Papadopoulos, K.H., Kalogiros, J.A., Kassomenos, P., Petrakis, M. (1999) Inland Propagation of Sea Breeze under Opposing Offshore Wind. Meteorology and Atmospheric Physics 70(1-2), 97-110.

Dandou, A., Tombrou, M., Soulakellis, N. (2009) The Influence of the City of Athens on the Evolution of the SBF. Boundary-Layer Meteorology 131(1), 35-51.

Gilliam, R.C., Raman, S., Niyogi, D.D.S. (2004) Observational and Numerical Study on the Influence of LargeScale Flow Direction and Coastline Shape on Sea-Breeze Evolution. Boundary-Layer Meteorology 111(2), 275-300.

Jeon, B.I. (1997) On Characteristic of SBF Observed in Pusan Coastal Area, Korea. Journal of Korean Environmental Science Society 6(6), 629-635.

Lee, D.I., Han, Y.H. (1992) Vertical Distribution of Aerosol Concentrations in the Boundary Layer Observed by a Tethered Balloon - Part II: Distributions of Aerosol Concentrations in Relation to the SBF. Asia-Pacific Journal of Atmospheric Sciences 28(4), 497-507.

Lee, T.Y. (1986) The effects of an inversion layer on the sea and land breeze circulations. Asia-Pacific Journal of Atmospheric Sciences 22(2), 48-61.

Mahrer, Y., Pielke, R.A. (1977) A numerical study of the airflow over irregular terrain. Beitrage zur Physik der Atmosphare 50(1-2), 98-113.

Malda, D., Arellano, J.V., Berg, W.D., Zuurendonk, I.W. (2007) The role of atmospheric boundary layer-surface interactions on the development of coastal fronts. Annals
Geophysics 25(2), 341-360.

Mellor, G.L., Yamada, T. (1982) Development of a turbulence closure model for geophysical fluid problems. Review of Geophysics and Space Physics 20, 851-875.

Miller, S.T.K., Keim, B.D., Talbot, R.W., Mao, H. (2003) Sea breeze: structure, forecasting, and impacts. Review of Geophysics and Space Physics 41(3), 1011, doi: 10.1029/2003RG000124.

Moon, J.Y., Park, S.-U., Song, C.K., Nakae, S. (1999) Effect of the Land-use Type on the Development of the Land and Sea Breeze in the Complex Coastal Region. Korean Journal Atmospheric Science 2(1), 45-58.

Pielke, R.A., Cotton, W.R., Walko, R.L., Trembaek, C.J., Lyons, W.A., Grasso, L.D., Nieholls, M.E., Moran, M.D., Wesley, D.A., Lee, T.J., Copeland, J.H. (1992) A Comprehensive Meteorological Modeling System-RAMS. Meteorology and Atmospheric Physics 49, 69-91.

Simpson, J.E. (1994) Sea Breeze and Local Wind. Cambridge University Press, pp. 27-44.

Suresh, R. (2007) Observation of SBF and its Induced Convection over Chennai in Southern Peninsular India Using Doppler Weather Radar. Pure and Applied Geophysics 164(8-9), 1511-1525.

Tremback, C.J. (1990) Numerical simulation of a mesoscale convective complex: Model development and numerical results. PhD Diss., Atmosphere Science Paper No 465, Colorado State University, Department of Atmospheric Science, Fort Collins, CO 80523.

(Received 25 March 2011, revised 4 July 2011, accepted 5 July 2011) 